\title{
The Effect of Wind-Turbine Wakes on Summertime US Midwest Atmospheric Wind Profiles as Observed with Ground-Based Doppler Lidar
}

\author{
Michael E. Rhodes · Julie K. Lundquist
}

Received: 11 November 2012 / Accepted: 17 June 2013 / Published online: 3 July 2013

(C) The Author(s) 2013. This article is published with open access at Springerlink.com

\begin{abstract}
We examine the influence of a modern multi-megawatt wind turbine on wind and turbulence profiles three rotor diameters $(D)$ downwind of the turbine. Light detection and ranging (lidar) wind-profile observations were collected during summer 2011 in an operating wind farm in central Iowa at 20 -m vertical intervals from 40 to $220 \mathrm{~m}$ above the surface. After a calibration period during which two lidars were operated next to each other, one lidar was located approximately $2 D$ directly south of a wind turbine; the other lidar was moved approximately $3 D$ north of the same wind turbine. Data from the two lidars during southerly flow conditions enabled the simultaneous capture of inflow and wake conditions. The inflow wind and turbulence profiles exhibit strong variability with atmospheric stability: daytime profiles are well-mixed with little shear and strong turbulence, while nighttime profiles exhibit minimal turbulence and considerable shear across the rotor disk region and above. Consistent with the observations available from other studies and with wind-tunnel and large-eddy simulation studies, measurable reductions in wake wind-speeds occur at heights spanning the wind turbine rotor (43-117 m), and turbulent quantities increase in the wake. In generalizing these results as a function of inflow wind speed, we find the wind-speed deficit in the wake is largest at hub height or just above, and the maximum deficit occurs when wind speeds are below the rated speed for the turbine. Similarly, the maximum enhancement of turbulence kinetic energy and turbulence intensity occurs at hub height, although observations at the top of the rotor disk do not allow assessment of turbulence in that region. The wind shear below turbine hub height (quantified here with the power-law coefficient) is found to be a useful parameter to identify whether a downwind lidar observes turbine wake or free-flow conditions. These field observations provide data for validating turbine-wake models and wind-tunnel observations, and for guiding assessments of the impacts of wakes on surface turbulent fluxes or surface temperatures downwind of turbines.
\end{abstract}

M. E. Rhodes · J. K. Lundquist $(\bowtie)$

Department of Atmospheric and Oceanic Sciences, 311 UCB, University of Colorado,

Boulder, CO 80309-0311, USA

e-mail: Julie.Lundquist@ colorado.edu

J. K. Lundquist

National Renewable Energy Laboratory, Golden, CO 80401, USA 
Keywords Diurnal cycle $\cdot$ Turbine wakes $\cdot$ Wind energy $\cdot$ Wind profiles $\cdot$ Lidar

\section{Introduction}

A global transition to renewable energy sources is possible due to abundant renewable resources and technology (Jacobson and Delucchi 2011). Wind energy is a leading renewable energy source for the United States (Milligan et al. 2009), partially due to the large wind resource that occurs in the US Midwest. The Midwest also serves as the hub of US agriculture (USDA 2012), so any potential impacts of wind turbines on agriculture could have significant economic effects. In particular, concern exists that increased turbulence in turbine wakes may alter surface temperatures (Zhou et al. 2012) or fluxes (Baidya Roy 2011) downwind. Additionally, turbulent wakes affect the energy production of turbines located downwind of other turbines (Barthelmie et al. 2007, among others). However, it is not yet known whether wind-turbine wakes have a beneficial or detrimental impact on crop growth (Rajewski et al. 2013) primarily due to the lack of detailed observations of the atmosphere and of the surface exchanges of heat, momentum, moisture, and carbon dioxide upwind and downwind of operational turbines. Such observations are essential to determine wake impact on the local environment.

A wind farm or wind plant, most commonly used for utility-scale applications, is a group of tens or hundreds of individual horizontal-axis wind turbines (typically of capacity 1.5 MW or greater) installed over an area on the order of many square kilometres. Typically, two to four turbines are found per $\mathrm{km}^{2}$ in modern wind plants. Each turbine in the wind farm has blades that produce electricity by converting horizontal momentum in the airflow into rotation of a generator. The area swept by the turbine blades is referred to here as the rotor disk. A region of reduced wind speeds and increased turbulence, called the wake, exists downwind of each turbine as a result of the interaction between the flow and rotor. Wakes from upwind turbines are responsible for decreased power output and increased turbine loading at downwind turbines in the wind farm (Frandsen 2007; Barthelmie et al. 2010, among others). Because turbine wakes have removed momentum from the flow, less momentum is available for the downwind turbines to extract.

Wind-turbine wakes induce atmospheric changes over a range of scales as documented through wind-tunnel studies, computer flow simulations, and field observations. Previous observational campaigns on turbines observe that downwind of a turbine there is a discernible wake region characterized by reduced horizontal wind speed and increased turbulence (Baker and Walker 1984; Hogström et al. 1988; Magnusson and Smedman 1994; Käsler et al. 2010; Trujillo et al. 2011; Iungo et al. 2013; Smalikho et al. 2013). Chamorro and Porté-Agel (2010) used a wind tunnel to determine the effects of a model wind turbine on fluid flow. Measuring mean and turbulence values of the flow under neutral conditions, they found signatures of turbine wakes at distances up to $20 \mathrm{D}$ downwind in the wind tunnel. Furthermore, they found the wake momentum deficit to be axially symmetric while wake-driven turbulence characteristics were concentrated above hub height. Wu and Porté-Agel (2011) compared these wind-tunnel simulations to neutrally stratified large-eddy simulations (LES) to identify optimal approaches for representing wind turbines in LES. While both LES and wind-tunnel studies provide insights into what might be expected from field campaigns, only field campaigns are able to capture real interactions between wind farms and atmosphere dynamics. Of course, test conditions such as wind speed and wind direction may not be controlled during a field campaign while they can be specified in a wind tunnel or in computational flow simulation. 
Turbine-wake measurement field campaigns often involve both in situ and remote sensing instrumentation. Standard atmospheric wind measurements are made with in situ measurements such as cup or sonic anemometers, which must be mounted on towers that can interfere with the measurements. Additionally, towers pose logistical problems due to the high measurement heights required to sample turbine wakes. Tethered kites and remotely piloted vehicles outfitted with onboard hotwire anemometers (Baker and Walker 1984; Hogström et al. 1988; Frehlich et al. 2003; Kocer et al. 2011) observe details of turbulence within wakes at multiple locations on the scale of seconds to minutes without the flow disruption of towers. Remote sensing technology, including acoustic, microwave, and laser systems, have the ability to observe turbine wakes at multiple locations. Lidar systems offer the ability to measure winds high above the ground and over long distances without having to erect a large meteorological tower at each measurement location.

In the present study, we aggregate over $100 \mathrm{~h}$ of lidar inflow and wake observations to document turbine mean and turbulent wake characteristics for a range of inflow wind speeds. Our dataset includes several cases of wakes occurring during nocturnal low-level jet conditions (Blackadar 1957; Whiteman et al. 1997; Banta et al. 2002). Section 2 qualifies the ability of this type of lidar to observe inhomogeneous flow such as wind-turbine wakes, and describes the observational dataset. Section 3 describes the undisturbed, or "inflow" wind and turbulence profiles to quantify the Midwest atmospheric boundary layer. In Sect. 4, we summarize the dependence of wake characteristics on inflow wind speed, and Sect. 5 highlights a case study of wake variability during nocturnal stable conditions; we emphasize this case because plentiful wind resources in the Midwest arise from the nocturnal low-level jet that occurs during such conditions. In Sect. 6 we compare the present results with those obtained in previous field studies, wind-tunnel studies, and simulations, and we suggest strategies for future lidar investigations of wind-turbine wakes.

\section{Observational Dataset}

As part of the Crop/Wind-energy EXperiment 2011 (CWEX-11) (Rajewski et al. 2013), two vertically profiling Doppler wind lidars (Windcube V1, described in Courtney et al. 2008) were deployed within an operating wind farm in the agricultural fields of central Iowa, USA (Fig. 1). Historical data indicate that this region often experiences strong southerly winds (Fig. 2), and so the lidars were sited north and south of a turbine to intentionally sample turbine inflow and wakes during southerly flow. Except during a brief intercomparison period, one lidar (CU1) was located approximately $165 \mathrm{~m}$ south (2.2D) of a row of six modern multimegawatt wind turbine generators (WTG) placed in a line running from west to east; the second lidar (CU2) was located 250 m north (3.4D) of the WTG row. In addition to the lidars, other equipment interrogated the effects of turbine wakes on the agricultural crops in the vicinity, including an array of two surface-flux stations south and north of the windturbine row, and an Integrated Surface Flux System (ISFS) south of the turbine row and an additional three ISFSs north of the turbines (NCAR ISFS 2012). Surface-flux data were recorded for the duration of the lidar operational period; these data are discussed in Rajewski et al. (2013). To focus on the turbine wakes specifically, only the lidar data are discussed here; future work will explore the impact of the wakes on surface quantities.

The WTG observed in this study is a GE 1.5 SLE, which has an 80-m hub height and 74-m rotor diameter extending from 43 to $117 \mathrm{~m}$ above ground level (a.g.l.). The turbine begins to rotate at a cut-in speed of $3 \mathrm{~m} \mathrm{~s}^{-1}$, below which no power is produced. Electrical power production reaches a maximum at $14 \mathrm{~m} \mathrm{~s}^{-1}$, the rated speed for the turbines. At speeds $>$ the 


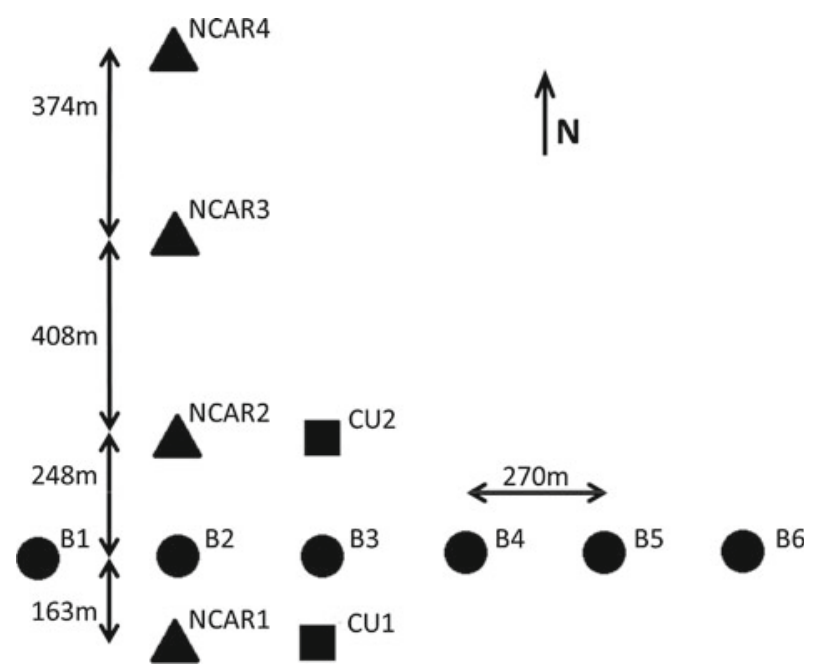

Fig. 1 A diagram of the field site shows an east-west row of wind turbines (B1-B6) indicated by circles. Square markers show the locations of each lidar system; triangles indicate the locations of NCAR surface-flux stations

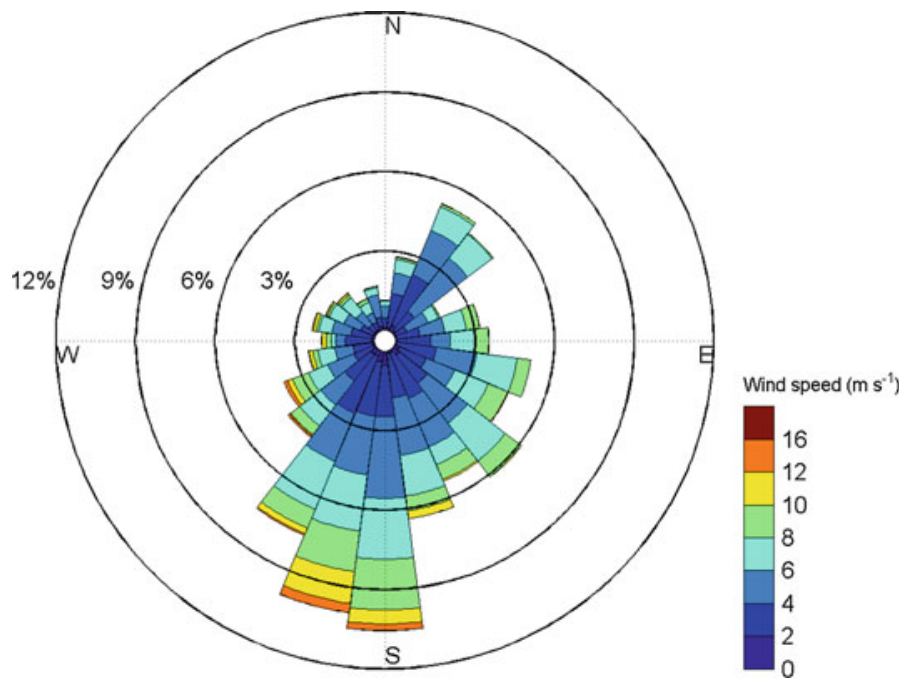

Fig. 2 A wind rose from the southern lidar measurements at $80 \mathrm{~m}$ a.g.l. indicates a predominantly southerly flow. Data from the entire observational period are included

rated speed, power production remains constant with increasing wind speed. At the cut-out speed of $25 \mathrm{~m} \mathrm{~s}^{-1}$, the turbine ceases rotation.

The row of WTGs pictured in Fig. 1 is located at the southern end of a larger utility-sized wind farm at an elevation of approximately $335 \mathrm{~m}$ above sea level. The landscape surrounding the study site consists of soybean and corn agricultural fields, with corn as the primary crop surrounding the lidars and WTGs. Small farms and homesteads interrupt the upwind fetch, with the closest homesteads approximately $600 \mathrm{~m}$ to the north-west and south-south-east from the lidars. A few metres north of the turbines and running parallel to the row of wind 
turbines, a 10-m-wide gravel access road connects the WTGs. The lidar observational period began on 30 June and concluded on 16 August 2011. Approximate sunrise occurred between 0430 and 0515 local standard time (LST) while sunset ranged from 1915 to 2000 LST.

The lidar system records the radial velocity of boundary-layer aerosols at a half opening angle $\phi$ (approximately $30^{\circ}$ from vertical) in each of the four cardinal directions once per second. Line-of-sight velocities at each of the lidar's ten range gates are converted to zonal, meridional, and vertical wind speeds at each height assuming flow homogeneity throughout the volume scanned by the lidar. (The impact of flow inhomogeneities on the measurements is discussed in Sect. 2.1.) The lidars record horizontal and vertical components of wind speed every second for each specified height; these components are then averaged for a 2-min period to quantify horizontal and vertical components of the flow and the variances of those quantities. Any data that do not meet the carrier-to-noise ratio threshold of $-22 \mathrm{~dB}$ are omitted from the recorded 2-min average. Wind shear, directional shear, horizontal turbulence intensity, vertical turbulence intensity, and a form of turbulent kinetic energy are calculated based on the 2-min data from the measured wind-speed components, wind direction, windspeed variance, and measurement height. Periods of precipitation (as measured at the local ISFS stations) are omitted due to potential lidar signal contamination (Aitken et al. 2012).

\subsection{Lidar Observations of Inhomogeneous Flow}

In the CWEX domain, the lidar observations of flow into the turbine can be assumed to be homogeneous across the measurement volume. However, observations in the wake region likely incorporate inhomogeneous flow, and so the uncertainty of lidar velocity measurements in such flow must be assessed. The size of the volume sampled by the lidar varies with the height $h$ of the measurement. For the Windcube v1 in the present campaign, $h$ ranged from 40 to $220 \mathrm{~m}$ a.g.l. With a half-opening angle $\phi$ of approximately $30^{\circ}$, the lineof-sight measurements at height $h$ are collected over a horizontal extent of $2 h \sin \phi$ (or approximately $h$ ). The effective probe length of the Windcube v1 is $18 \mathrm{~m}$. Therefore, at an altitude of $40 \mathrm{~m}$, the Windcube velocity measurements collected over a 4-s period represent a volume $40 \mathrm{~m}$ in the horizontal, $18 \mathrm{~m}$ in the vertical, and centered at $40 \mathrm{~m}$ above the surface. Similarly, at an altitude of $100 \mathrm{~m}$, the Windcube velocity measurements collected over a 4-s period represent a volume $100 \mathrm{~m}$ in the horizontal, $18 \mathrm{~m}$ in the vertical, centered at $100 \mathrm{~m}$ above the surface.

At hub height (here, $80 \mathrm{~m}$ elevation), a turbine wake has a horizontal extent or width the size of the rotor disk (approximated here as $80 \mathrm{~m}$ ); at either 60 or $100 \mathrm{~m}$ a.g.l., the wake width would be approximately $70 \mathrm{~m}$. Very few measurements of wake expansion have been documented, but in the offshore wind farm Horns Rev, wakes have been observed to expand by $5-10^{\circ}$ as they move downwind (Barthelmie et al. 2010). With a $5^{\circ}$ wake expansion, the wake region at $80 \mathrm{~m}$ a.g.l. would expand to approximately $124 \mathrm{~m}$ wide by the time the wake reaches the downwind lidar located at $3.4 D(250 \mathrm{~m})$ downwind, so that the wake will encompass the entire Windcube sampling volume at that elevation. Similarly, the wake at $100 \mathrm{~m}$ above the surface would expand to $114 \mathrm{~m}$ width at a location $3.4 \mathrm{D}$ downwind of the turbine, and so the wake would again envelop the Windcube sampling volume. Therefore, it is reasonable to assume that for southerly flow, the downwind lidar samples turbine wake at all altitudes $100 \mathrm{~m}$ and below. The measurement volume of the downwind lidar may exceed that of the wake itself at $120 \mathrm{~m}$ a.g.l., and so information on the transverse component of the flow in the wake at the top of the rotor disk cannot be collected with certainty using the experimental design here. However, the estimates of the streamwise velocity would be collected within the wake. (We are hopeful that estimates of wake expansion will become 
more precise based on observational studies in the future, particularly studies using scanning Doppler lidar (Käsler et al. 2010; Iungo et al. 2013; Smalikho et al. 2013) or radar (Hirth and Schroeder 2013).)

It is useful to quantify wake characteristics throughout the rest of the rotor disk, $100 \mathrm{~m}$ and below, recognizing that the measurements are likely sampling inhomogeneous flow. Bingöl et al. (2008) quantified lidar measurement uncertainty due to inhomogeneous flow for the special case of the mean velocity field varying linearly across the measurement volume defined by the half-opening angle $\phi$ (nominally $30^{\circ}$ for the Windcube v1). They found the lidar measurements of the zonal $(u)$, meridional $(v)$ and vertical $(w)$ velocity components at measurement altitude $h$ have an uncertainty given by a function only of the variation of the vertical velocity $w$ as it varies in the zonal $(x)$, meridional $(y)$, and vertical $(z)$ components:

$$
\begin{aligned}
& u_{\text {lidar }}(h)=u(h)+h \frac{\partial w(h)}{\partial x}, \\
& v_{\text {lidar }}(h)=v(h)+h \frac{\partial w(h)}{\partial y}, \\
& w_{\text {lidar }}(h)=w(h)-\frac{h}{2 \cos (\varphi)} \tan ^{2}(\varphi) \frac{\partial w(h)}{\partial z} .
\end{aligned}
$$

In inhomogeneous flow, then, the uncertainty of velocity measurements is a function of the variation in vertical velocity across the horizontal extent ( $x$ or $y$ ) of the measurement volume. Note that, although variations in the horizontal velocities are permitted in this model, by continuity those terms may be replaced with variations in the vertical velocity as shown in Bingöl et al. (2008). The horizontal extent ( $x$ or $y$ ) of the measurement volume is, by virtue of $\varphi \approx 30^{\circ}$, approximately $h$, simplifying (1)-(3) after discretization of the partial derivatives to

$$
\begin{aligned}
u_{\text {lidar }}(h) & =u(h)+\Delta w(h), \\
v_{\text {lidar }}(h) & =v(h)+\Delta w(h), \\
w_{\text {lidar }}(h) & =w(h)-\frac{h}{3 \sqrt{ } 3} \frac{\Delta w(h)}{\Delta z},
\end{aligned}
$$

where $\Delta z$ is the effective probe length of the Windcube, $18 \mathrm{~m}$ (Courtney et al. 2008). Therefore, uncertainties in the lidar estimates of the horizontal velocity components are on the order of the vertical velocity variation within the wake. Uncertainties in the vertical velocity measurements are a function of the magnitude of the vertical velocity and $h /(3 \sqrt{ } 3 \Delta z)$ where the denominator $\approx 94 \mathrm{~m}$. To quantify uncertainty of lidar measurements in inhomogeneous flow, then, it is important to quantify the variation of vertical velocity in a wake.

Using two Doppler lidars, Iungo et al. (2013) report observations of the horizontal and vertical velocity components in the wake of a $2.3 \mathrm{MW}$ turbine, which is larger than the turbine studied here. They find "the mean vertical velocity is shown to be roughly negligible for all the tested downstream locations," consistent with the modeling studies of Porte-Agel et al. (2011) and Wu and Porté-Agel (2011). Close inspection of the figures of Iungo et al. (2013) suggests a variation of vertical velocity in the wake of less than $0.7 \mathrm{~m} \mathrm{~s}^{-1}$. Therefore, according to Eqs. 4 and 5, we expect an error of $<1 \mathrm{~m} \mathrm{~s}^{-1}$ in the horizontal wind-speed measurements within the wake reported herein, for measurements at heights $100 \mathrm{~m}$ and below. More detailed quantification of lidar uncertainty, perhaps using detailed computational fluid dynamics simulations, may be possible. 


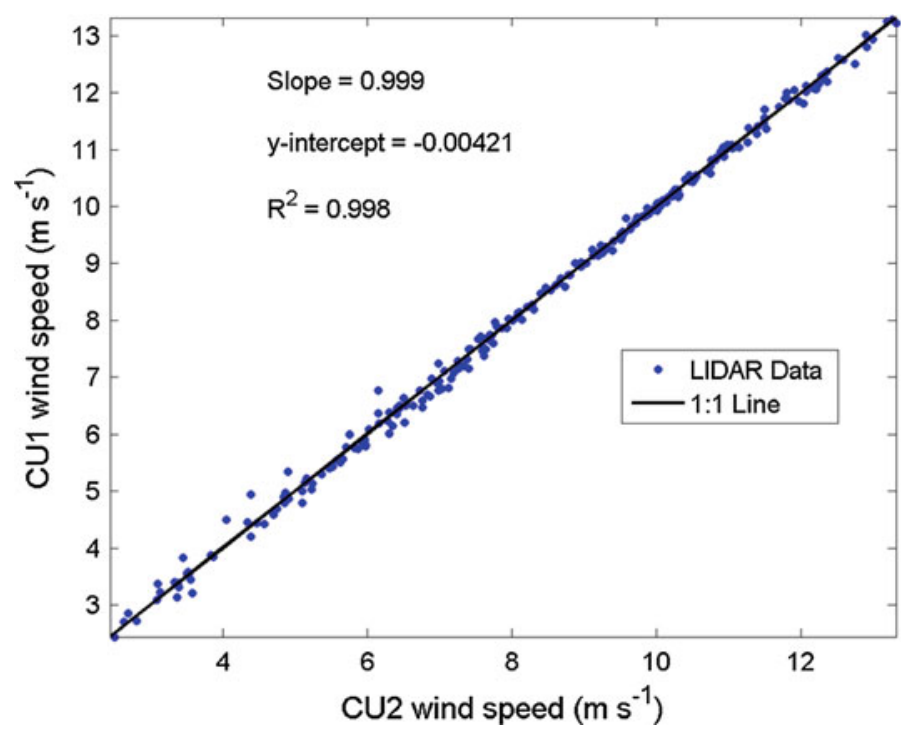

Fig. 3 Hub-height comparison of 10-min average horizontal wind speed for the two lidar units at the upwind site during the 2-day intercomparison period

\subsection{Lidar Intercomparison}

The two lidars were co-located during the first two days of the 2011 observational campaign to quantify any bias in wind-speed measurement between the two lidar units. Both units were sited at the CU1 site (Fig. 1) separated by approximately $3 \mathrm{~m}$. During the intercomparison, wind speeds were less than $20 \mathrm{~m} \mathrm{~s}^{-1}$ and wind direction was mostly from the south-southwest, unaffected by any turbines. 10-min averaged wind speeds from both units compare well (Fig. 3): the slope is near unity and the $y$-intercept of the ordinary least-squares best fit is close to zero. A high coefficient of determination, 0.998, shows a strong correlation between the data from each lidar. $R^{2}$ values between the lidar units exceeded 0.997 when comparing wind speed and direction at all heights within the rotor disk. Both wind-speed and wind-direction data are highly correlated between the two lidars at all heights during the intercomparison. We conclude there was no detectable bias in wind speed between the two instruments. After the intercomparison period, the lidars were located at their respective locations shown in Fig. 1 to capture both upwind and wind-turbine wake data.

\subsection{Wake Definition}

During the CWEX observational campaign, wind direction was frequently (but not always) from the south (Fig. 2). Using the hub-height wind speed and wind direction as measured by the upwind lidar (CU1), we define periods when the northerly lidar (CU2) likely sampled the turbine wake. Requirements included a CU1 wind speed $>3 \mathrm{~m} \mathrm{~s}^{-1}$ (to ensure turbine operation). A wind direction requirement based on the wake expansion of 5-10 observed by Barthelmie et al. (2010) was calculated: wind directions between $167^{\circ}$ and $195^{\circ}$ should place a wake from turbine B3 (Fig. 1) directly over the lidar at CU2 so that all four beams from the lidar sample wake. Other wind directions produce wakes from other turbines; the analysis here incorporates only wakes from turbine B3, located directly between the two lidars. 
In excess of 4,000 10-min time periods are available for analysis; more than 600 time periods $(6,000 \mathrm{~min})$ meet the criteria based on wind speed, wind direction, and precipitation for a wind-turbine wake detected by the lidar. Approximately half of the data presented here $(55 \mathrm{~h})$ were collected between the hours of 0700 and $1900 \mathrm{LST}$, providing an even distribution of daytime and nighttime conditions.

\subsection{Quantities Observed}

From the 2-min estimates of the two horizontal components $(u, v)$ and the vertical component $(w)$ of wind velocity, as well as the variances of these quantities over the 2-min period, several useful quantities can be calculated. 10-min averages of these quantities are presented in the figures below.

Previous investigations have observed enhanced turbulence intensity in the wake. Turbulence intensity is calculated from the variances $\left(\sigma^{2}\right)$ of the $u$ and $v$ components of the flow as in Eq. 7,

$$
I=\frac{\sqrt{\sigma_{u}^{2}+\sigma_{v}^{2}}}{U},
$$

where $U$ is the mean horizontal wind speed (Stull 1988) at the level at which the velocities are observed. (Note that some investigators focusing on wind-tunnel studies, such as Chamorro and Porté-Agel (2009), normalize turbulence intensity with hub-height wind speed rather than the wind speed at the altitude of the measurement.) In the wind energy industry, turbulence intensity is usually calculated over a 10-min period, although it is likely that other averaging times are more appropriate for capturing all the energetic length scales of turbulent fluctuations (Mahrt 1998).

These variances may also be used to calculate a quantity approximating turbulent kinetic energy (TKE), a measure of turbulence in the atmosphere (Eq. 8). TKE incorporates both horizontal and the vertical components of flow variability (Stull 1988), and so an estimate of lidar TKE (here $E$ ) can be calculated as,

$$
E=0.5\left(\sigma_{u}^{2}+\sigma_{v}^{2}+\sigma_{w}^{2}\right) .
$$

In a detailed comparison of tower-based sonic anemometry to ground-based lidar, Sathe et al. (2011) suggest that ground-based lidar systems fail to accurately calculate horizontal and vertical variances as compared to sonic anemometry. Without tower data for comparison here, we do not suggest that the lidar can directly calculate TKE as it would be measured by a sonic anemometer. Rather, we provide a comparison between two similar lidar systems as they quantify fluctuations in the wind as represented by $E$.

The wind profile power law (Eq. 9) compares wind-speed measurements between two heights $z_{i}$ and $z_{i+1}$. The power law is used in the wind energy industry not because it is an accurate portrayal of the true wind profile, but because the resulting coefficient $\alpha$ captures information about wind shear that is easily comparable between multiple geographic locations (Schwartz and Elliott 2006),

$$
\frac{U_{i+1}}{U_{i}}=\left(\frac{z_{i+1}}{z_{i}}\right)^{\alpha} .
$$

In neutral stability, $\alpha=1 / 7$ is commonly used for approximations (Brower 2012). This assumption does not hold true for strongly stable or strongly unstable atmospheric conditions or under high wind shear conditions (Walter et al. 2009; Wharton and Lundquist 2012a,b, among others). Large positive values of $\alpha$ indicate a large increase of wind speed with height; 
negative values indicate a decrease of wind speed with height. Changes of wind direction with height are not captured by the power-law coefficient. As discussed in the references above, the use of $\alpha$ to quantify wind shear is not optimal, as it implicitly assumes a logarithmic wind profile that may only be expected in the surface layer or under neutral stratification. Herein it is used only to facilitate comparisons with previous work. Wherever possible, we recommend quantification of the complete wind-speed and wind-direction profiles rather than analysis of only a power-law coefficient $\alpha$ calculated between two levels.

\section{Atmospheric Boundary-Layer Properties as Observed with Lidar}

Before examining the properties of the waked or disturbed wind profile, it is useful to characterize the upwind or unwaked wind profile to assess averaged atmospheric boundary-layer characteristics of the summertime Midwest boundary layer. We focus on time periods with southerly flow (wind directions between $150^{\circ}$ and $210^{\circ}$ ); this span of wind directions is slightly larger than that used by the wake characterization study in Sect. 4. Because of data loss due to variations in power-generator performance, precipitation events, wind-direction shifts, and air quality, data availability varies with time of day and of height (Fig. 4a): however, at least 30 data points contribute to information at each height and time of day, with over 50 data points in many cases.

An increase of wind speed with height at all times of day is observed (Fig. 4b), as would be expected near the surface. Between 0800 and 1600 local time, the increase of wind speed with height is subtle, between 2 and $3 \mathrm{~m} \mathrm{~s}^{-1}$ between 40 and $220 \mathrm{~m}$ above the surface: convective mixing during the daytime ensures only slight variations of wind speed with height. During nocturnal conditions, on the other hand, strong variations of wind speed with height occur, with wind-speed differences up to $9 \mathrm{~m} \mathrm{~s}^{-1}$ between 40 and $220 \mathrm{~m}$ above the surface. The nocturnal wind-speed profiles are consistent with those expected when nocturnal low-level jets are present (Banta et al. 2002, among others). Similarly, the wind direction (Fig. 4c) exhibits subtle variations (approximately $5^{\circ}$ ) during well-mixed daytime conditions. However, the nocturnal decoupling of the boundary layer is accompanied by strong wind-direction shifts in excess of $35^{\circ}$ between the top and bottom heights sampled by the lidar.

Turbulence intensity, as measured by the upwind lidar, exhibits a classic pattern of strong turbulence during the day and reduced turbulence at night (Fig. 4d). Note that because wind speeds are reduced during the day (Fig. 4b), the turbulence intensity is enhanced during the day. When $E$ is considered, daytime values also exceed nocturnal values (figure not shown). This regular diurnal pattern is also evident in the time series of the change of wind direction with height (Fig. 4e), presented here as calculated across the turbine rotor disk (between 40 and $120 \mathrm{~m}$ ). These data are presented for the contrast with observations of minimal veer documented in northern European sites (Cariou et al. 2010). The lidar data suggest strong daytime convective turbulence couples flow at lower levels with that at upper levels, so little variation in wind speed or direction occurs during the day. Nighttime conditions, with minimal turbulence and no mixing, enable the decoupling and resulting acceleration and veering of winds at upper levels.

The power-law coefficient, which measures the variation of wind speed with height, also exhibits strong diurnal variability (Fig. 4f) when calculated either across the turbine rotor disk (between 40 and $120 \mathrm{~m}$ ) or across the extent sampled by the lidar (between 40 and $220 \mathrm{~m}$ ). Note that the lowest measurement available from the lidar is at $40 \mathrm{~m}$ above the surface, and so these $\alpha$ values are lower than would be expected for comparison to other studies that calculate 

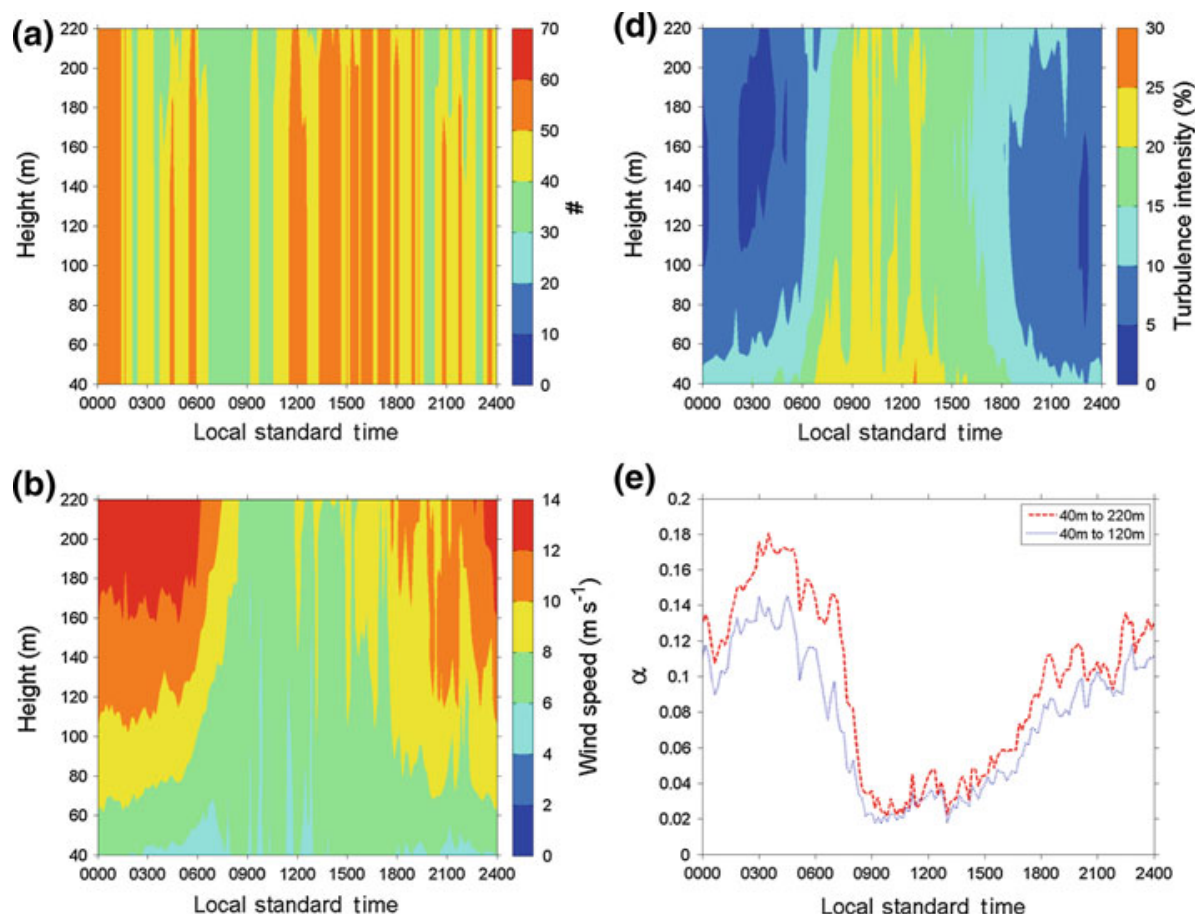

(e)

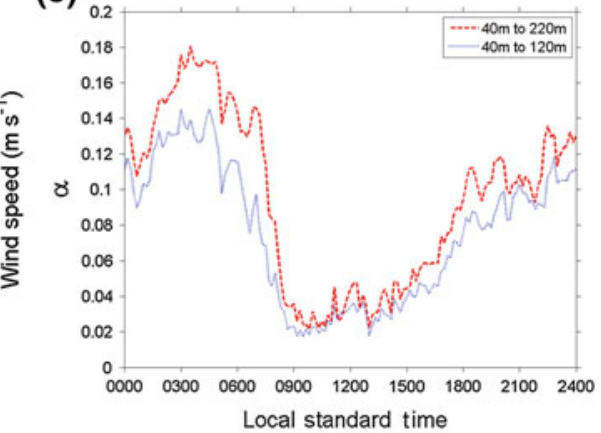

(c)
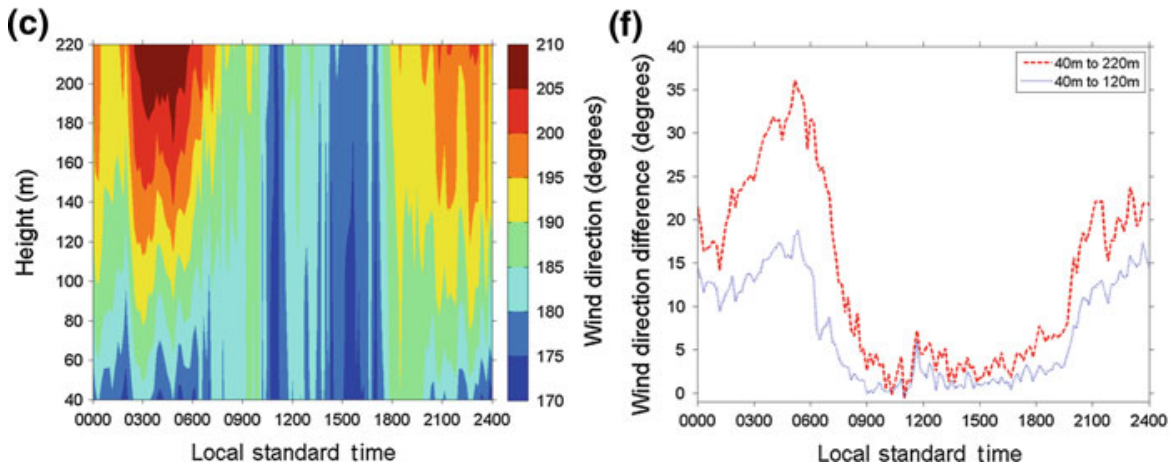

Fig. 4 10-min averages of a data availability, $\mathbf{b}$ median wind speed, $\mathbf{c}$ mean wind direction, $\mathbf{d}$ turbulence intensity, e power-law coefficient, and $\mathbf{f}$ wind-direction difference for times with hub-height wind directions ranging between $150^{\circ}$ and $210^{\circ}$

shear between a surface-layer measurement (10 m, for example) and altitudes at the turbine rotor disk (Walter et al. 2009). The marked diurnal variations in atmospheric stability are an important trait of atmospheric behaviour in the US Midwest region.

\section{Wake Properties Vary with Inflow Wind Speed}

Wake characteristics are expected to depend on inflow wind speed and elevation within the rotor disk. 10-min mean differences of horizontal wind speed and turbulence intensity data were categorized based on the upwind wind speed at the time of the difference measurement. 
Upwind wind-speed bins are defined in $0.5 \mathrm{~m} \mathrm{~s}^{-1}$ increments from 2 to $16 \mathrm{~m} \mathrm{~s}^{-1}$, the available range of wind speeds observed throughout the 7-week study period during southerly flow conditions. At least twenty 10-min data points contribute to each unique wind-speed and height bin presented here.

\subsection{Wake Wind-Speed Deficit}

The magnitude of the wind-speed deficit in the wake has been found to vary with altitude within the wake in field measurements (Baker and Walker 1984; Hogström et al. 1988; Chamorro and Porté-Agel 2010; Käsler et al. 2010). The wind-tunnel observations of Cal et al. (2010) and LES of Wu and Porté-Agel (2011) find a maximum deficit at hub height, as do the lidar observations of Iungo et al. (2013). We also find the average wake deficit exhibits largest values at or just above hub height (80-100 m) (Fig. 5a). The magnitude of the deficit depends on the upwind wind speed, with the maximum deficit occurring at wind speeds just below rated speed, on the order of $10 \mathrm{~m} \mathrm{~s}^{-1}$. These observations are consistent with expectations for pitch-control turbines such as those studied here: although the turbine will extract the maximum amount of energy at wind speeds below rated, at wind speeds above the rated speed the blades pitch so that no additional power is generated as the wind speed increases. At wind speeds above the rated speed, blades are pitched to extract less momentum from the flow and the wind-speed deficit can be smaller than at lower wind speeds.

\subsection{Wake Turbulence Intensity Enhancement}

Previous investigations have observed enhanced turbulence intensity in the wake. This region of enhanced turbulence increases damaging loads on downwind turbines. Further, if this enhanced turbulence penetrates to the surface, it may modify surface-atmosphere exchanges of heat, momentum, moisture, and carbon dioxide. We observe a distinct region of turbulence enhancement at turbine hub height (Fig. 5b). As with the wind-speed deficit, the largest enhancement of turbulence occurs at wind speeds below rated. Other observations have noted turbulence enhancement also at the top of the rotor disk (Iungo et al. 2013). Given that our measurement volume at the top of the rotor disk is possibly sampling non-wake flow as discussed in Sect. 2.1, the measurements here do not support or deny the existence of enhanced turbulence at the top of the rotor disk.

\section{Stable Nighttime Case Study}

Stable conditions are of particular interest for wake studies, as wakes are expected to retain their integrity and propagate for longer distances during stable conditions, as compared to convective conditions in which strong background turbulence may erode a wake rapidly (Fitch et al. 2013). A night with consistent southerly flow during the CWEX campaign allows close examination of wake impacts during stable conditions. The nocturnal case study began at 2100 LST on 16 July 2011 and concluded at 0700 LST on 17 July 2011; sunset occurred at 1947 LST on 16 July, and sunrise followed at 0452 LST on 17 July. Weather conditions during the event consisted of southerly flow at wind-turbine hub height with wind-direction variations from $170^{\circ}$ to $195^{\circ}$ (Fig. 6). Average hub-height wind speeds were about $9 \mathrm{~m} \mathrm{~s}^{-1}$ and decreased throughout the night to $7 \mathrm{~m} \mathrm{~s}^{-1}$ with some variation. Synoptically, Iowa was situated between an anticyclone to the east and a weak low pressure system to the north-west, which resulted in southerly winds observed at hub height. 

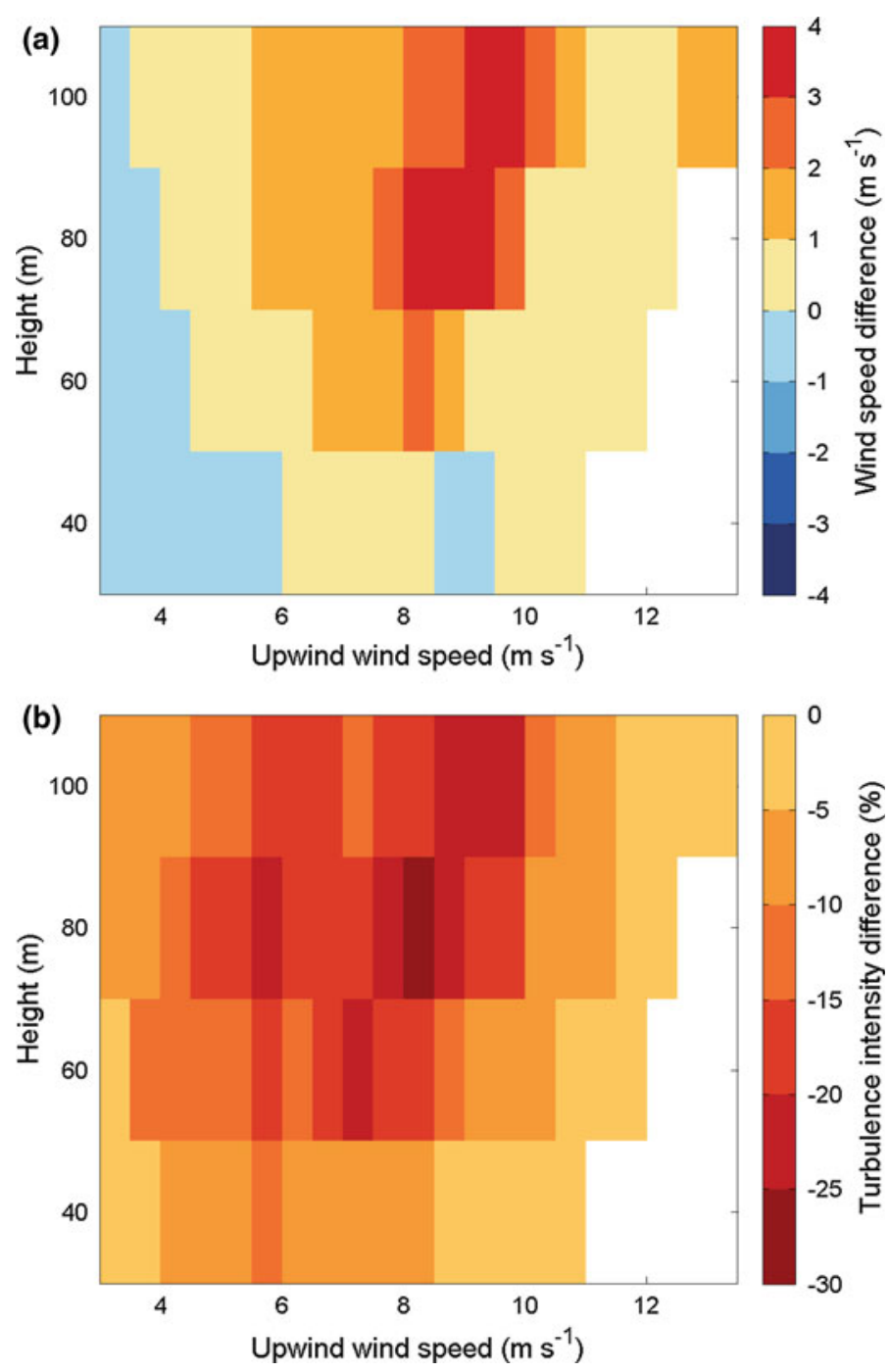

Fig. 5 Upwind wind speed-height contours of a mean wind speed and $\mathbf{b}$ mean turbulence intensity differences due to the turbine wake ( $2 D$ upwind $-3 D$ downwind) for all stability conditions. $D$ is the rotor diameter, or $74 \mathrm{~m}$ for this study. A minimum of 202 -min data points were required in each bin

\subsection{Wake Effects on Wind Speed}

The wind-speed deficit during the nighttime case study (Fig. 7) varied with both inflow wind speed and inflow wind direction. From 2230 until 0230 LST, the maximum wind-speed deficit at three rotor diameters downwind was located at $100 \mathrm{~m}$ above the surface, not at hub height, but rather in the top half of the rotor disk. The wake deficit was observed between 40 and $140 \mathrm{~m}$, thereby extending above the top of the rotor disk at $120 \mathrm{~m}$. The reduced wind speeds above the rotor disk suggest a vertically expanding turbine wake, which is unexpected during these stable conditions. 


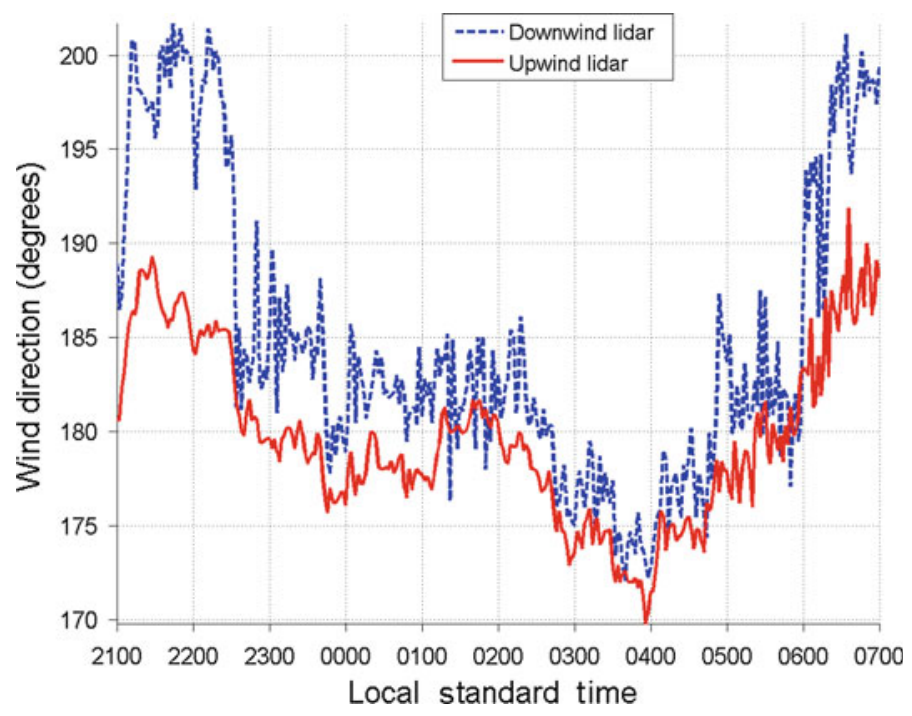

Fig. 6 Wind directions (2-min averages) at $80 \mathrm{~m}$ observed by the upwind and downwind lidars over the night of 16-17 July 2011

Beginning at 0300 and concluding near 0500 LST, the wind direction shifted from a southerly flow to a more south-south-easterly flow. With this change in flow direction, the downwind wind-speed deficit was reduced, though still present, and because of this winddirection shift, the downwind lidar (CU2) detected the edge of the wake.

\subsection{Wake Enhancement of Turbulence Kinetic Energy}

For most of the night, the upwind lidar observed TKE (as represented by $E$ ) values $<0.5 \mathrm{~m}^{2} \mathrm{~s}^{-2}$ at all heights; $E$ only began to increase in magnitude after sunrise at 0600 (Fig. 8). Throughout the night, the downwind lidar observed $E$ to be approximately five times larger than values upwind. Larger values of $E$ occurred frequently near the 80-m hub height but were seen throughout the rotor disc region by the downwind lidar. When the wind direction shifted to the south-east at 0245-0445 LST, the height of maximum $E$ increased to around $100 \mathrm{~m}$, although the overall values of $E$ were reduced as the lidar likely sampled the edge of the wake during this time period. At both the downwind and upwind lidars, the large increase of $E$ beginning shortly after 0600 was due to development of daytime convective conditions after sunrise at 0452 LST.

\subsection{Wake Enhancement of Turbulence Intensity}

Much like TKE, turbulence intensity values increase in the lee of a wind-turbine rotor due to increased turbulent flow in the wake. Turbulence intensity is presented here because it is commonly used in the wind industry when performing a wind resource assessment or turbine suitability studies (Brower 2012). As with E, upwind turbulence intensities (Fig. 8a) were small at all heights throughout the night and only begin to increase at sunrise. However, the downwind turbulence intensity (Fig. 8b) in the rotor disc region remained large throughout the night. For wind directions between $185^{\circ}$ and $190^{\circ}$ (2130-2230 LST), the downwind lidar observed increased turbulence intensity in the lower half of the rotor disc between 40 and $80 \mathrm{~m}$ (as compared to the upwind lidar observations). Then from 2230 until 0300 LST with 

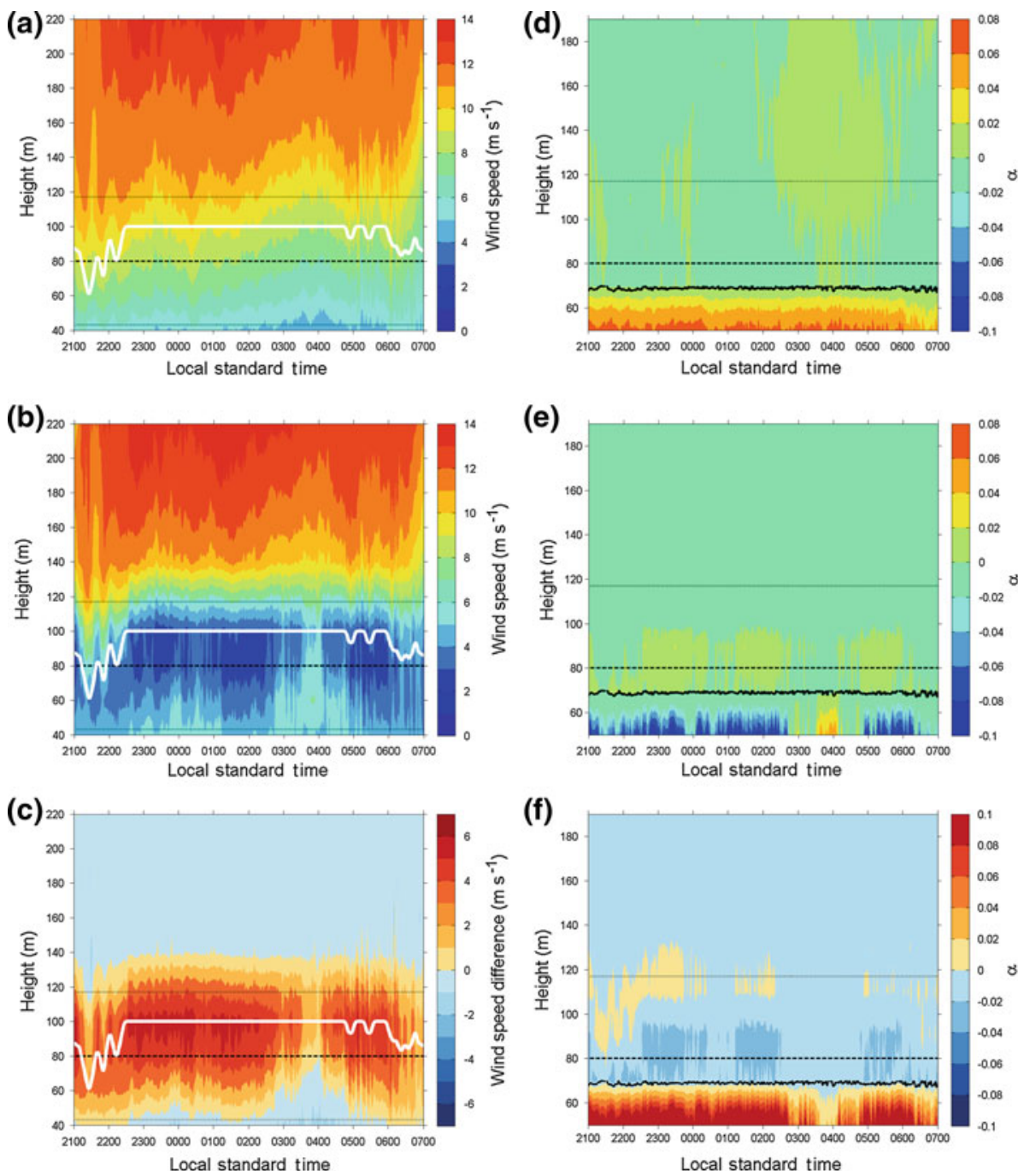

Fig. 7 Time-height contours of a upwind, b downwind, and $\mathbf{c}$ upwind-downwind difference of horizontal wind speed, and $\mathbf{d}$ upwind, e downwind, and $\mathbf{f}$ upwind-downwind difference of power-law coefficient $\alpha$ over the night of 16-17 July 2011 calculated from 2-min averages. Dotted lines indicate edge of the rotor disk and dashed lines show turbine-hub height. The solid white line indicates $(\mathbf{a}-\mathbf{c})$ the greatest difference of wind speed on a 20-min average basis. The solid black line (d-f) shows the lowest height between positive and negative wind-shear difference

wind direction from $170^{\circ}$ to $175^{\circ}$, the largest values of turbulence intensity occurred at the 80-m level, with high values throughout the entire rotor. During the wind shift to slightly easterly flow, from 0300 to 0445 LST, the downwind lidar continued to observe increased turbulence intensity as compared to the upwind lidar observations, although the magnitude of the enhancement was smaller than when the flow was more southerly. After sunrise, a further deepening of the turbulent layer was evident in both the upwind and downwind datasets, though the largest values of turbulence intensity downwind were still in the top half of the rotor disc area. 

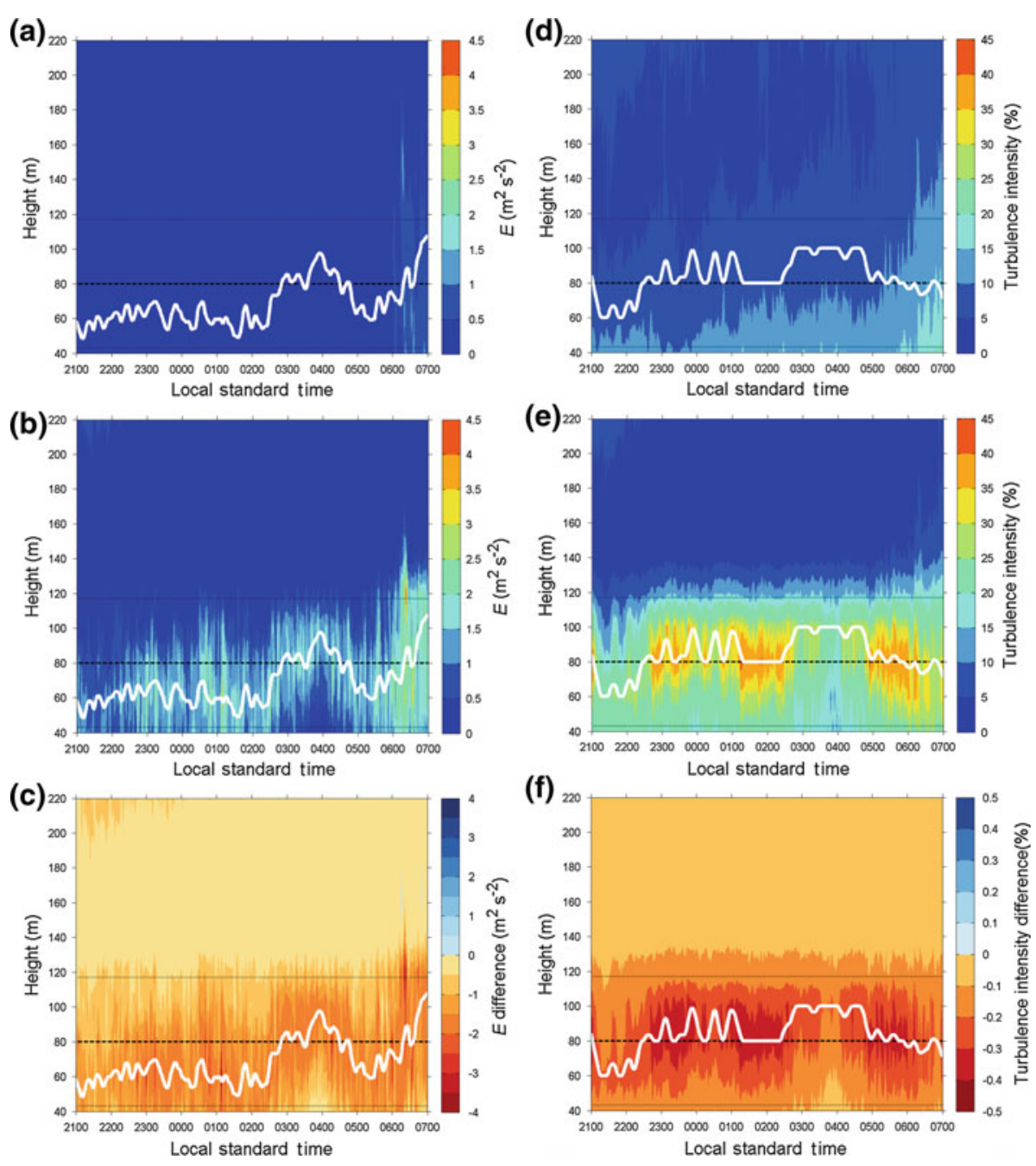

Fig. 8 Time-height contours of a upwind, b downwind, and $\mathbf{c}$ upwind-downwind difference of the lidardetermined $E$, and $\mathbf{d}$ upwind, e downwind, and $\mathbf{f}$ upwind-downwind difference of horizontal turbulence intensity over the night of 16-17 July 2011 calculated from 2-min averages. Dotted lines indicate edge of the rotor disk and dashed lines show turbine-hub height. The solid white lines indicate the greatest difference upwind versus downwind on a 20-min average basis

\subsection{Wake Impacts on the Power-Law Coefficient $\alpha$}

Upwind $\alpha$ values (Fig. 7d) remained near zero for most of the heights observed, but below $70 \mathrm{~m}, \alpha$ increased to between 0.02 and 0.08 , reflecting the strong wind shear closer to the surface as the wind speed increased with height. Downwind (Fig. 7e), 50-70 $\mathrm{m} \alpha$ exhibited negative values between -0.1 and -0.02 from 50 to $70 \mathrm{~m}$, indicating that wind speeds in the bottom half of the rotor disk decreased with height due to the momentum extraction from the turbine. Between 70 and $100 \mathrm{~m}, \alpha$ ranged from 0.02 to 0.04 , indicating increasing wind speeds with height. Of note, this pattern changes during the easterly wind shift around 
0330 to 0400 LST where the values of $\alpha$ resembled values observed upwind of the turbine, suggesting that during this time period, the lidar did not sample a turbine wake. Additionally, the distinct sign change of the power-law coefficient during a period when the wake was not sampled suggests the utility of $\alpha$ (or the sign of wind shear) as a parameter for determining wake versus non-wake conditions.

\section{Discussion and Conclusions}

Wind turbines have a measureable effect on atmospheric flow as determined using data from wind-profiling lidars located approximately two rotor diameters $(160 \mathrm{~m})$ upwind and three rotor diameters $(240 \mathrm{~m})$ downwind of a multi-MW three-bladed horizontal axis wind-turbine generator (WTG). The "undisturbed" flow upwind of the turbine in this summertime US Midwest location is marked by a strong diurnal cycle of moderate and daytime winds with little shear and strong nocturnal low-level jets with considerable shear; the nocturnal flow shows evidence of changes in wind direction on the order of $20^{\circ}$ across typical turbine rotordisk altitudes. We find reduced wind speed, enhanced TKE, and enhanced turbulence intensity within the wake, and that the characteristics of the wake vary with inflow wind speed.

After quantifying the error that can be expected from lidar measurements of inhomogeneous flow in the turbine wake, over $100 \mathrm{~h}$ of data were aggregated to quantify the variability of the wake as a function of inflow wind speed. At all wind speeds, the height of maximum wind-speed reduction is at hub height or the range gate immediately above the hub. In neutrally stratified wind-tunnel observations, Chamorro and Porté-Agel (2009) found the maximum wind speed reduction at $3 \mathrm{D}$ downwind to be very close to hub height. Similarly, $\mathrm{Cal}$ et al. (2010) report a wake-velocity minimum at hub height. In reporting other measurements of wakes in the atmosphere, various authors have asserted that maximum velocity deficits occur below hub height (Elliott and Barnard 1990), at hub height (Kambezidis et al. 1990), "somewhat" above hub height (Magnusson and Smedman 1994; Helmis et al. 1995) or "near" hub height (Barthelmie et al. 2003). The results found here are thus consistent with the wide range reported previously. Further, we find that the maximum deficit occurs at wind speeds just below the rated wind speed for the turbine, consistent with expectations based on the variation in the tip-speed ratio and thrust coefficient of the turbine (Elliott and Barnard 1990; Magnusson and Smedman 1994; Helmis et al. 1995; Barthelmie et al. 2007).

The turbine wake is also characterized by enhanced turbulence, which can induce large loads and stresses on downwind turbines. We find the height of maximum TKE enhancement to be at hub height in both a 100-h aggregation of wake characteristics and in a stable boundary-layer case study, with the caveat that observations at the top of the rotor disk are not available due to the measurement volume of the lidar at that altitude. Using neutral boundary-layer wind-tunnel observations, Chamorro and Porté-Agel (2009) found the height of maximum turbulence enhancement to be above hub height, in the top half of the rotor disk, associated with the high turbulence levels produced by the turbine blade-tip vortices. The present observations differ in that we see the turbulence intensity and the TKE at maximum levels closer to hub height in both stable conditions and unstable conditions, in contrast to the neutral conditions used in the wind tunnel. The wind-tunnel measurements and the LES of Wu and Porté-Agel (2011) normalize turbulence intensity by the hub-height inflow value instead of the value at that height. (We have also normalized our data by hub-height inflow values (not shown), and find no meaningful difference with the data presented here.) Cal et al. (2010) found maximum Reynolds shear stresses in the wake in the top half of the rotor disk. As shown in their Fig. 15, the streamwise velocity variance is at a maximum 
in the centre of the top half of the disk, while the vertical velocity variance also has a maximum value in the top of the rotor disk. Other field investigations (Magnusson and Smedman 1994) have noted two distinct maxima in the turbulence profile of the wake, attributed to the tip vortices off the blades, at distances of approximately four rotor diameters downwind.

Our case study emphasizes that observations of the wake are highly dependent on the inflow wind direction: subtle changes in wind direction were sufficient to remove the wake from the sampling volume of the lidar. The sign of the wind-speed shear (often expressed as $\alpha$, the power-law coefficient) in the lower half of the rotor disk (between 50 and $70 \mathrm{~m}$ ) is a useful determinant of wake versus non-wake downwind conditions. Because momentum extraction in the rotor disc region produces negative shear in the lower half of the rotor, the shear is a clear indicator of the wind-turbine wake and may prove a more precise tool than upwind wind direction for definition of wake periods for fixed downwind measurements. The strong effect of the wake on the shear of the lower boundary layer has also been observed in the wind-tunnel study of Cal et al. (2010). We conclude that evaluating the sign of the wind shear is a simple identifier for wake conditions and is potentially of use for quantifying wake behaviour and propagation.

The present work has provided insight into the impact of turbine wakes on the atmosphere at one location downwind of a single turbine. To understand the spatial extent of turbine wakes and their evolution downstream, however, future field studies should incorporate scanning lidar to investigate how a wake evolves far downwind of a turbine (Käsler et al. 2010; Iungo et al. 2013; Smalikho et al. 2013). Scanning lidar captures information across a vertical profile of the wake or horizontal scans that span wake and non-wake conditions over tens of seconds. Additionally, use of a radiometer or instrumented tall tower to measure temperature and moisture profiles in the atmospheric boundary layer would allow for better understanding of stability conditions and impacts of the turbine wake on the moisture flux (Friedrich et al. 2012). In situ flux measurements of moisture, heat, or trace gases from meteorological towers that span the distance between standard 10-m meteorological stations and the 40-m lowest lidar measurement level would provide a more complete understanding of how wind-turbine wakes propagate to, and interact with, the surface. Field observations such as these provide data critical for validating turbine-wake models (Churchfield et al. 2012) and wind-tunnel observations, and for guiding assessments of the impacts of wakes on surface fluxes or surface temperatures downwind of turbines.

Acknowledgments The authors gratefully acknowledge the efforts of our collaborators in the CWEX experiment, including the Iowa State Team of Dr. Gene Takle, Dan Rajewski, Russ Doorenbos, Kris Spoth, Jimmy Cayer, and the NCAR team including Dr. Steve Oncley and Dr. Tom Horst. We also extend appreciation to the wind farm operators and the landowners who permitted the deployment of the lidar systems, and to Dr. Branko Kosović, Ms. Alice DuVivier, Dr. Andrew Clifton, and Mr. Brian Vanderwende for useful discussions and suggestions. We express appreciation for the helpful comments of two anonymous reviewers. This work was supported by the National Renewable Energy Laboratory under APUP UGA-0-41026-22. NREL is a national laboratory of the US Department of Energy, Office of Energy Efficiency and Renewable Energy, operated by the Alliance for Sustainable Energy, LLC.

Open Access This article is distributed under the terms of the Creative Commons Attribution License which permits any use, distribution, and reproduction in any medium, provided the original author(s) and the source are credited.

\section{References}

Aitken ML, Rhodes ME, Lundquist JK (2012) Performance of a wind-profiling lidar in the region of wind turbine rotor disks. J Atmos Ocean Technol 29:347-355 
Baidya Roy S (2011) Simulating impacts of wind farms on local hydrometeorology. J Wind Eng Ind Aerodyn 99:491-498

Baker RW, Walker SN (1984) Wake measurements behind a large horizontal axis wind turbine generator. Sol Energy 33:5-12

Banta RM, Newsom RK, Lundquist JK, Pichugina YL, Coulter RL, Mahrt L (2002) Nocturnal low-level jet characteristics over Kansas during CASES-99. Boundary-Layer Meteorol 105(2):221-252

Barthelmie RJ, Folkerts L, Ormel FT, Sanderhoff P, Eecen PJ, Stobbe O, Nielsen NM (2003) Offshore wind turbine wakes measured by SODAR. J Atmos Ocean Technol 20:466-477

Barthelmie RJ, Frandsen ST, Nielsen MN, Pryor SC, Rethore P-E, Jørgensen HE (2007) Modelling and measurements of power losses and turbulence intensity in wind turbine wakes at Middelgrunden offshore wind farm. Wind Energy 10:517-528

Barthelmie RJ, Pryor SC, Frandsen ST, Hansen KS, Schepers JG, Rados K, Schlez W, Neubert A, Jensen LE, Neckelmann S (2010) Quantifying the impact of wind turbine wakes on power output at offshore wind farms. J Atmos Ocean Technol 27:1302-1317

Bingöl F, Mann J, Foussekis D (2008) Modeling conically scanning lidar error in complex terrain with WAsP engineering. Danmarks Tekniske Universitet, Ris $\varnothing$ Nationallaboratoriet for Bæredygtig Energi, 2008. 16 pp (Denmark. Forskningscenter Risoe. Risoe-R; No. 1664(EN)). http://orbit.dtu.dk/services/ downloadRegister/3332817/ris-r-1664.pdf

Blackadar AK (1957) Boundary layer wind maxima and their significance for the growth of nocturnal inversions. Bull Am Meteorol Soc 38:283-290

Brower M (2012) Wind resource assessment. Wiley, New York

Cal RB, Lebrón J, Castillo L, Kang HS, Meneveau C (2010) Experimental study of the horizontally averaged flow structure in a model wind-turbine array boundary layer. J Renew Sustain Energy 2:013106-1013106-25

Cariou N, Wagner R, Gottschall J (2010) Analysis of vertical wind direction and speed gradients for data from the Met. Mast at Høvsøre. Danmarks Tekniske Universitet, Ris $\varnothing$ Nationallaboratoriet for Bæredygtig Energi. 34 pp. http://www.risoe.dk/en/Knowledge_base/publications/Reports/ris-r-1733.aspx?sc_lang=da

Chamorro LP, Porté-Agel F (2009) A wind-tunnel investigation of wind-turbine wakes: boundary-layer turbulence effects. Boundary-Layer Meteorol 132:129-149

Chamorro LP, Porté-Agel F (2010) Effects of thermal stability and incoming boundary-layer flow characteristics on wind-turbine wakes: a wind-tunnel study. Boundary-Layer Meteorol 136:515-533

Churchfield MJ, Lee S, Michalakes J, Moriarty PJ (2012) A numerical study of the effects of atmospheric and wake turbulence on wind turbine dynamics. J Turbul 13:1-32

Courtney M, Wagner R, Lindelöw P (2008) Testing and comparison of lidars for profile and turbulence measurements in wind energy. IOP Conf Ser Earth Environ Sci 1:012021. doi:10.1088/1755-1315/1/1/ 012021

Elliott DL, Barnard JC (1990) Observations of wind turbine wakes and surface roughness effects on wind flow variability. Sol Energy 45:265-283

Fitch A, Lundquist JK, Olson JB (2013) Mesoscale influences of wind farms throughout a diurnal cycle. Mon Weather Rev (in press). doi:10.1175/MWR-D-12-00185.1

Frandsen ST (2007) Turbulence and turbulence-generated structural loading in wind turbine clusters. 135 pp. http://www.risoe.dtu.dk/rispubl/VEA/veapdf/ris-r-1188.pdf

Frehlich R, Meillier Y, Jensen ML, Balsley B (2003) Turbulence measurements with the CIRES tethered lifting system during CASES-99: calibration and spectral analysis of temperature and velocity. J Atmos Sci 60:2487-2495

Friedrich K, Lundquist JK, Aitken M, Kalina EA, Marshall RF (2012) Stability and turbulence in the atmospheric boundary layer: a comparison of remote sensing and tower observations. Geophys Res Lett 39:1-6

Helmis CG, Papadopoulos KH, Asimakopoulos DN, Papageorgas PG, Soilemes AT (1995) An experimental study of the near-wake structure of a wind turbine operating over complex terrain. Sol Energy 54:413-428

Hirth BD, Schroeder JL (2013) Documenting wind speed and power deficits behind a utility-scale wind turbine. J Appl Meteorol Climatol 52:39-46. doi:10.1175/JAMC-D-12-0145.1

Hogström DA, Kambezidis H, Helmis C, Smedman A (1988) A field study of the wake behind a 2 MW wind turbine. Atmos Environ 22:803-820

Iungo GV, Wu Y-T, Porté-Agel F (2013) Field measurements of wind turbine wakes with lidars. J Atmos Ocean Technol 30:274-287. doi:10.1175/JTECH-D-12-00051.1

Jacobson MZ, Delucchi MA (2011) Providing all global energy with wind, water, and solar power, part I: technologies, energy resources, quantities and areas of infrastructure, and materials. Energy Policy 39:1154-1169 
Kambezidis HD, Asimakopoulos DN, Helmis CG (1990) Wake measurements behind a horizontal-axis 50 kW wind turbine. Sol Wind Technol 7:177-184

Käsler Y, Rahm S, Simmet R, Kühn M (2010) Wake measurements of a multi-MW wind turbine with coherent long-range pulsed doppler wind lidar. J Atmos Ocean Technol 27:1529-1532

Kocer G, Mansour M, Chokani N, Abhari RS, Muller M (2011) Full-scale wind turbine near-wake measurements using an instrumented uninhabited aerial vehicle. J Sol Energy Eng 133:041011-1-041011-8

Magnusson M, Smedman AS (1994) Influence of atmospheric stability on wind turbine wakes. Wind Eng 18:139-151

Mahrt L (1998) Flux sampling errors for aircraft and towers. J Atmos Ocean Technol 15:416-429. doi:10. 1175/1520-0426(1998)0150416:FSEFAA2.0.CO;2

Milligan M, Lew D, Corbus D, Piwko R, Miller N, Clark K, Jordan G, Freeman L, Zavadil B, Schuerger M (2009) Large-scale wind integration studies in the United States: preliminary results. NREL/CP-55046527, $8 \mathrm{pp}$

Porte-Agel F, Wu Y-T, Lu H, Conzemius R (2011) Large-eddy simulation of atmospheric boundary layer flow through wind turbines and wind farms. J Wind Eng Ind Aerodyn 99:154-168

Rajewski DA et al (2013) Crop wind energy experiment (CWEX): observations of surface-layer, boundary layer, and mesoscale interactions with a wind farm. Bull Am Meteorol Soc 94:655-672

Sathe A, Mann J, Gottschall J, Courtney MS (2011) Can wind lidars measure turbulence? J Atmos Ocean Technol 28:853-868

Schwartz MN, Elliott DL (2006) Wind shear characteristics at central plains tall towers. National Renewable Energy Laboratory, $13 \mathrm{pp}$

Smalikho IN, Banakh VA, Pichugina YL, Brewer WA, Banta RM, Lundquist JK, Kelley ND (2013) Lidar investigation of atmosphere effect on a wind turbine wake. J Atmos Ocean Technol. doi:10.1175/ JTECH-D-12-00108.1

Stull RB (1988) An introduction to boundary-layer meteorology. Kluwer, Dordrecht, 666 pp

Trujillo J-J, Bingöl F, Larsen GC, Mann J, Kühn M (2011) Light detection and ranging measurements of wake dynamics. Part II: Two-dimensional scanning. Wind Energy 14:61-75

USDA (2012) US county crop harvest. http://www.nass.usda.gov/Charts_and_Maps/Crops_County/index.asp

Walter K, Weiss CC, Swift AHP, Chapman J, Kelley ND (2009) Speed and direction shear in the stable nocturnal boundary layer. J Sol Energy Eng 131:011013-1-011013-7

Wharton S, Lundquist JK (2012a) Atmospheric stability affects wind turbine power collection. Environ Res Lett 7:014005-1-014005-9

Wharton S, Lundquist JK (2012b) Assessing atmospheric stability and its impacts on rotor-disk wind characteristics at an onshore wind farm. Wind Energy 15:525-546

Whiteman CD, Bian X, Zhong S (1997) Low-level jet climatology from enhanced rawindsonde observations at a site in the southern Great Plains. J Appl Meteorol 36:1363-1376

Wu Y-T, Porté-Agel F (2011) Large-eddy simulation of wind-turbine wakes: evaluation of turbine parametrisations. Boundary-Layer Meteorol 138:345-366

Zhou L, Tian Y, Roy SB, Thorncroft C, Bosart LF, Hu Y (2012) Impacts of wind farms on land surface temperature. Nat Clim Chang 2:539-543 